\title{
Performance Analysis of C I Engine with Dual Fuel Mode for different Speeds.
}

\author{
E.Ramjee ${ }^{1} \quad$ K.Vijaya kumar Reddy ${ }^{2} \quad$ J.suresh kumar ${ }^{3}$ \\ 1. Associate Professor in Mechanical Engineering, JNTUH College of Engineering, Hyderabad. \\ 2\&3. Professor of Mechanical Engineering, JNTUH College of Engineering, Hyderabad
}

\begin{abstract}
Rapid depletion of conventional energy sources, along with increasing demand for energy is a matter of serious concern for the mankind. The factor that petroleum based fuels will neither be available in sufficient quantities nor at a reasonable price in future, has revived interest in exploring the use of alternative fuels. It is essential that these alternative fuels for engine should be drive from indigenous sources and preferable renewable energy sources.

In this work, experiments are conducted by governing pilot fuel and speed for defined loads. in the present work, the engine performance characteristics are computed using $C N G$ as the main fuel and diesel as the pilot fuel of dual fuel mode. From the experimental investigations, it is concluded that the engine performance of the dual fuel operation is better than the diesel fuel operation.
\end{abstract}

\section{Introduction:}

India's energy needs are growing with economic development and growing population. The indigenous energy resources may not be sufficient in the long run to sustain the process of economic development of $9 \%$ of Gross Domestic Product. The country's energy supply system continues to be dependent on fossil fuels, which are finite. The oil and gas share in the energy consumption has reached a level of about $45 \%$ and is expected to remain so. Globally also the share of oil is expected to remain at the same level in future also.

The industrial growth of any country is measured by the amount of energy generation as well as its consumption. The fuel-air mixture before combustion and the burned products after combustion are the actual working fluids. The work transfers which provide the desired power output occur directly between these working fluids and the mechanical components of the engine. Because of their simplicity, ruggedness and high power-to-weight ratio, the Internal Combustion engines have found wide range of applications in agriculture, transportation and power sectors.

The strategy to implement alternative fuels in Internal Combustion engines is becoming the subject of interest nowadays. The reasons are driven by the energy independence from petroleum based fuel [2]. Among the alternative fuels, CNG has been recognized as one of the promising alternative fuel due to its substantial benefits compared to gasoline and diesel [4]. However, the number of Vehicles powered by this alternative fuel is still small compared to the number of conventional vehicles that powered by gasoline and diesel. In the case of gaseous engine, from 5.5 millions - only one million used CNG and the rest used LPG [1].

The main objectives of this project is to study the effects of using CNG as an alternative fuel as a replacement for diesel in compression ignition engines. In the present work, diesel is used as the pilot fuel to ignite CNG and CNG as the main fuel. The impact of injection pressure is to be observed at constant and variable loads with different engine speeds to study the engine performance characteristics. In the present work, comparison analysis is to be carried out with diesel and dual fuel operation.

\section{EXPERIMENTATION}

The experimental setup consists of a single-cylinder, four-stroke, vertical water cooled, direct injection, natural aspirated, diesel engine connected to water brake dynamometer for loading of the engine. Experiments were conducted with pure diesel and dual fuel mode (diesel+CNG) at different engine speeds ranging from 800 $\mathrm{rpm}$ to $1300 \mathrm{rpm}$ [3]. Provision is also made for interfacing air flow, fuel flow, temperatures and speed measurement [5]. The emphasis is on comparison of the engine performance with Diesel alone and dual fuel mode (diesel $+\mathrm{CNG})$. The layout of experimental set up is shown in figure 1 . 


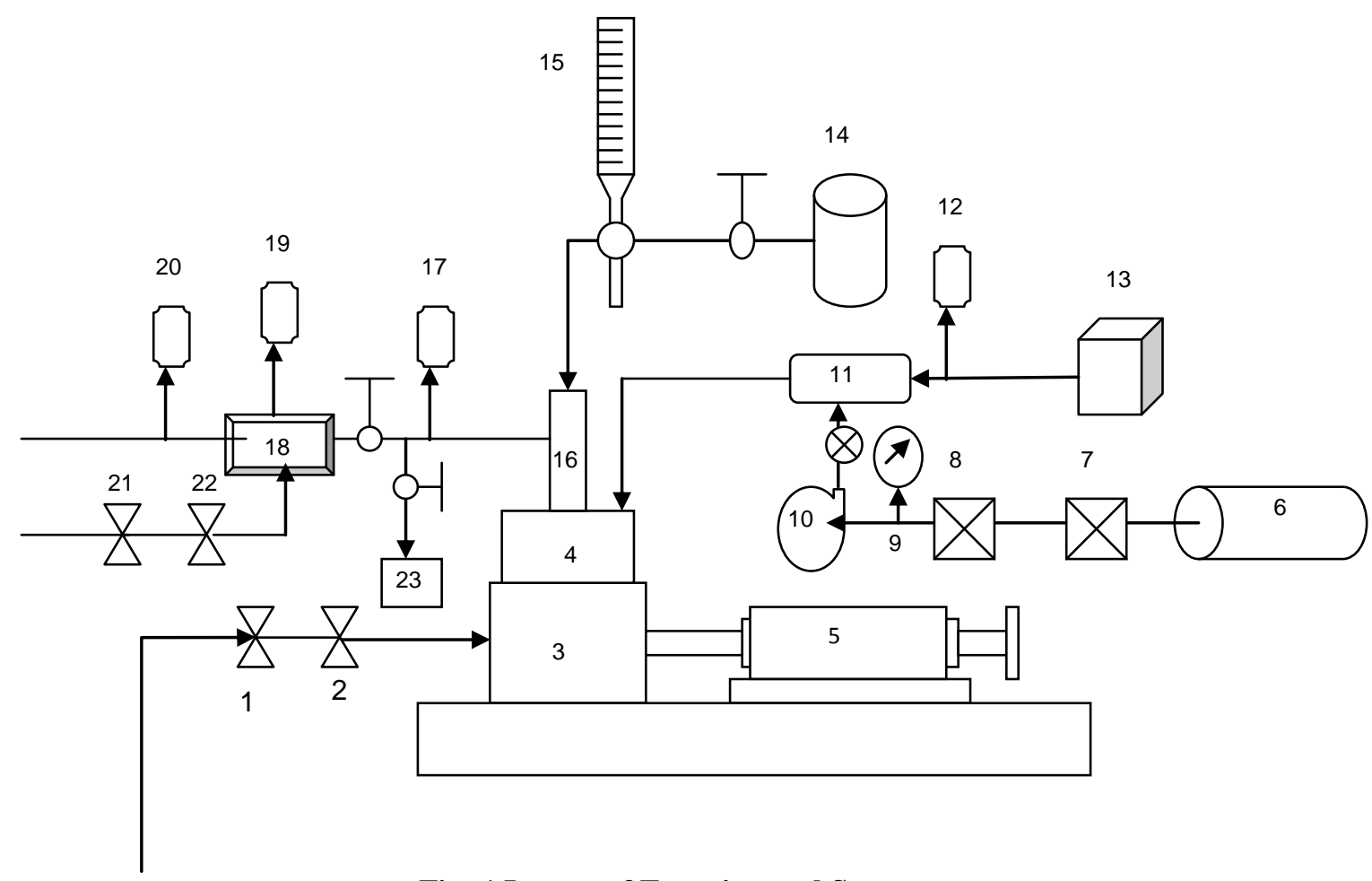

Fig: 1 Layout of Experimental Set up

[1. Cooling Water flow meter 2. Inlet water temperature Sensor 3. Engine block 4. Cylinder head 5. Hydraulic Dynamo meter 6. CNG cylinder 7. ON/OFF Valve 8. Solenoid valve 9. Pressure gauge 10. Regulator 11. Gasair mixer 12. Manometer 13. Air box 14. Fuel tanks 15. Diesel flow measuring unit 16. Fuel injection system 17. Exhaust gas temperature sensors at inlet calorimeter 18. Calorimeter 19. Calorimeter outlet water temperature sensors 20. Temperature at outlet calorimeter 21. Calorimeter water flow meter 22. Calorimeter inlet water temperature sensor 23. Emissions analyzer point].

\section{Results and Discussion}

The results from the experiments performed on the single cylinder, four-stroke, direct injection diesel engine operating at maximum load are shown from fig 2 to 6 and discussed below.

From the graph 2, it is concluded that the exhaust gas temperature is increases with increase in engine speed. The exhaust gas temperature of diesel fuel is higher than dual-fuel, with an average difference of $20.3^{0} \mathrm{C}$. The high exhaust temperature of diesel engines compared to dual-fuel will result in unfavourably higher NOx emission and also indicates that combustion of dual-fuel is leaner than diesel since less heat is usually produced during lean combustion.

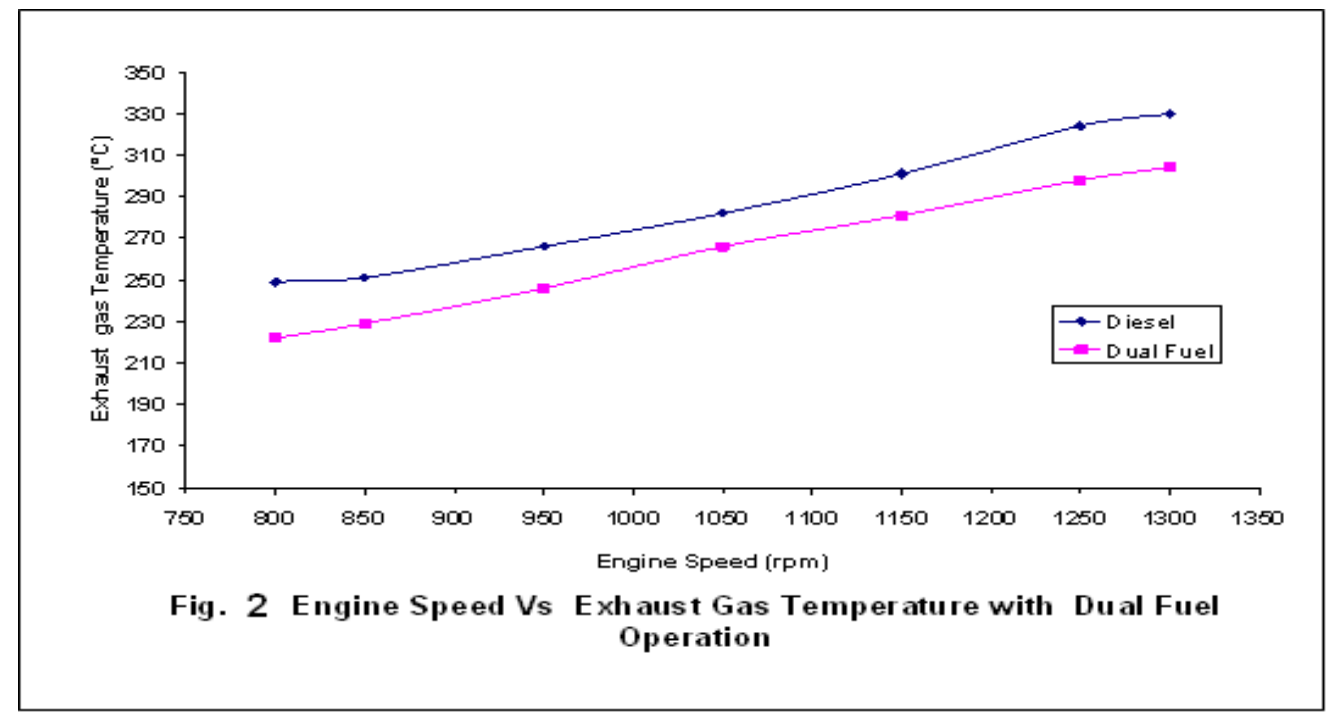




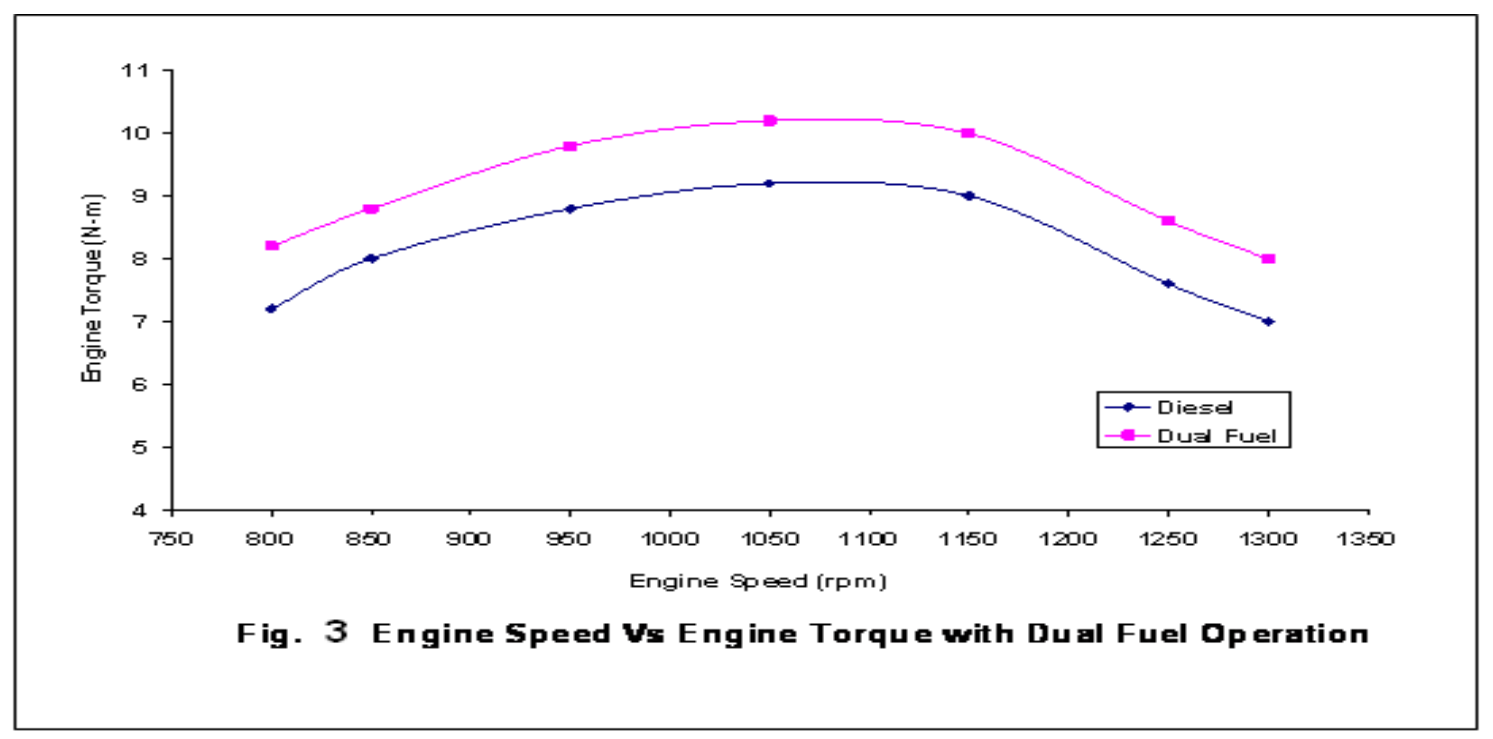

Figure 3 shows that the torque increases for engine speeds ranging from $800 \mathrm{rpm}$ to $1300 \mathrm{rpm}$ to a peak before dropping in magnitude for higher speeds up to 1500rpm for both diesel and dual-fuel. It is observed from the figure 3 , that the measured value from the dynamometer shows a higher torque for dual-fuel operation for all engine speeds. As engine speed is increased from $800 \mathrm{rpm}$ to $1300 \mathrm{rpm}$, the measured torque for diesel and dualfuel increases indicating a higher fuel flow rate into the combustion chamber and an increased energy input available to the engine. The engine output torque drops tremendously for engine speed of $1300 \mathrm{rpm}$ due to engine knocking.

From the figure 4, the engine brake power produced for dual-fuel operation is higher than diesel fuel operation with a maximum value difference of $0.272 \mathrm{~kW}$ recorded at the engine speed of $1300 \mathrm{rpm}$. The engine brake power produced decreases slightly due to engine knocks at the speed of $1300 \mathrm{rpm}$ for both diesel and dual fuel.

From the Fig 5, it is observed that the fuel consumption per unit power output for dual fuel is lower than diesel fuel with the maximum occurring at $1300 \mathrm{rpm}$ with $17.1 \%$ reduction. It is also observed that the specific fuel consumption decreases when the engine Speed is increased from $800 \mathrm{rpm}$ to around $1050 \mathrm{rpm}$, and then shows a slight increment for speeds above $1050 \mathrm{rpm}$ due to the engine knocks.

From the figure 6, it is found that the thermal efficiency of the engine running with dual-fuel is higher compared to diesel fuel for engine speeds ranging from $800 \mathrm{rpm}$ to $1300 \mathrm{rpm}$ due to higher heating value of natural gas.

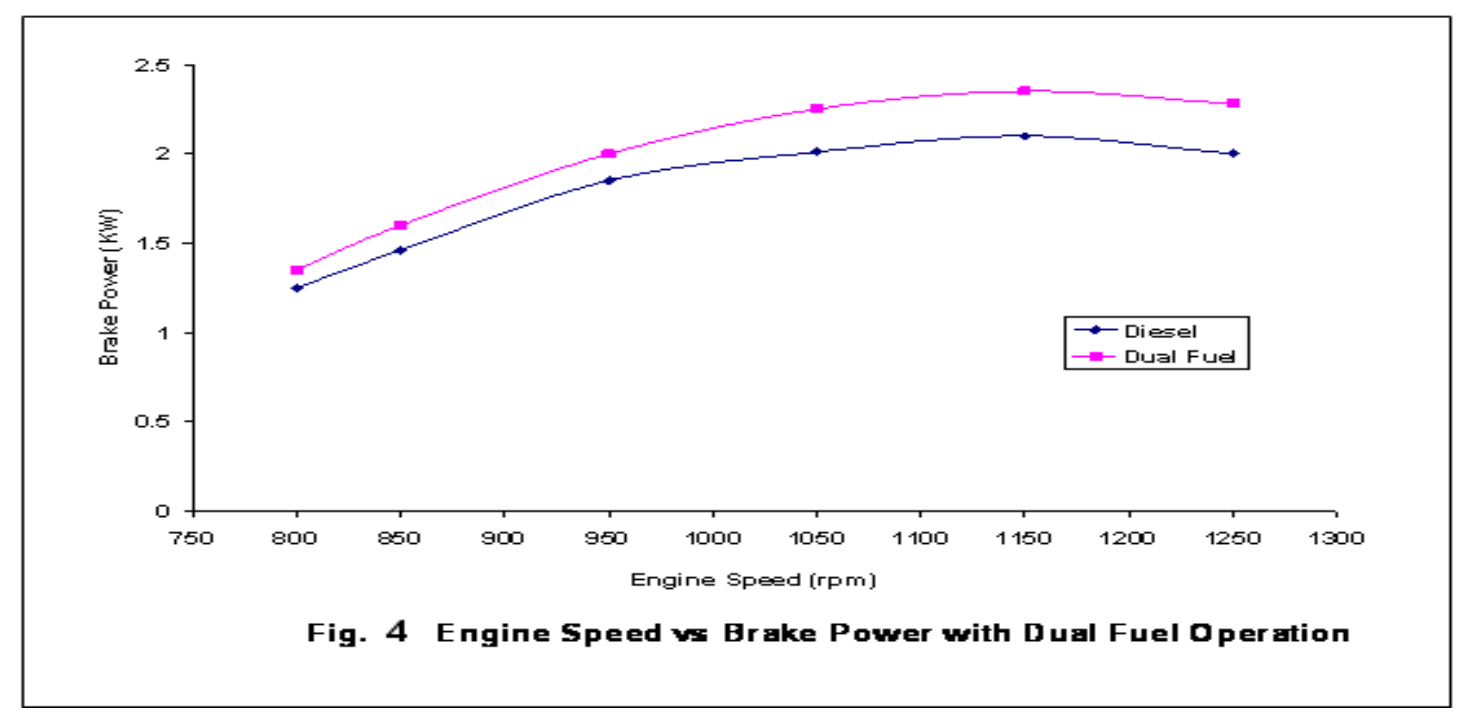

At engine speeds higher than $1300 \mathrm{rpm}$, the brake thermal efficiency begins to decrease slightly due to the effects of engine knocks which not only causes output power losses but also damages the engine. The design of the engine needs to be modified to prevent engine knocking and substantially improves the fuel economy. 

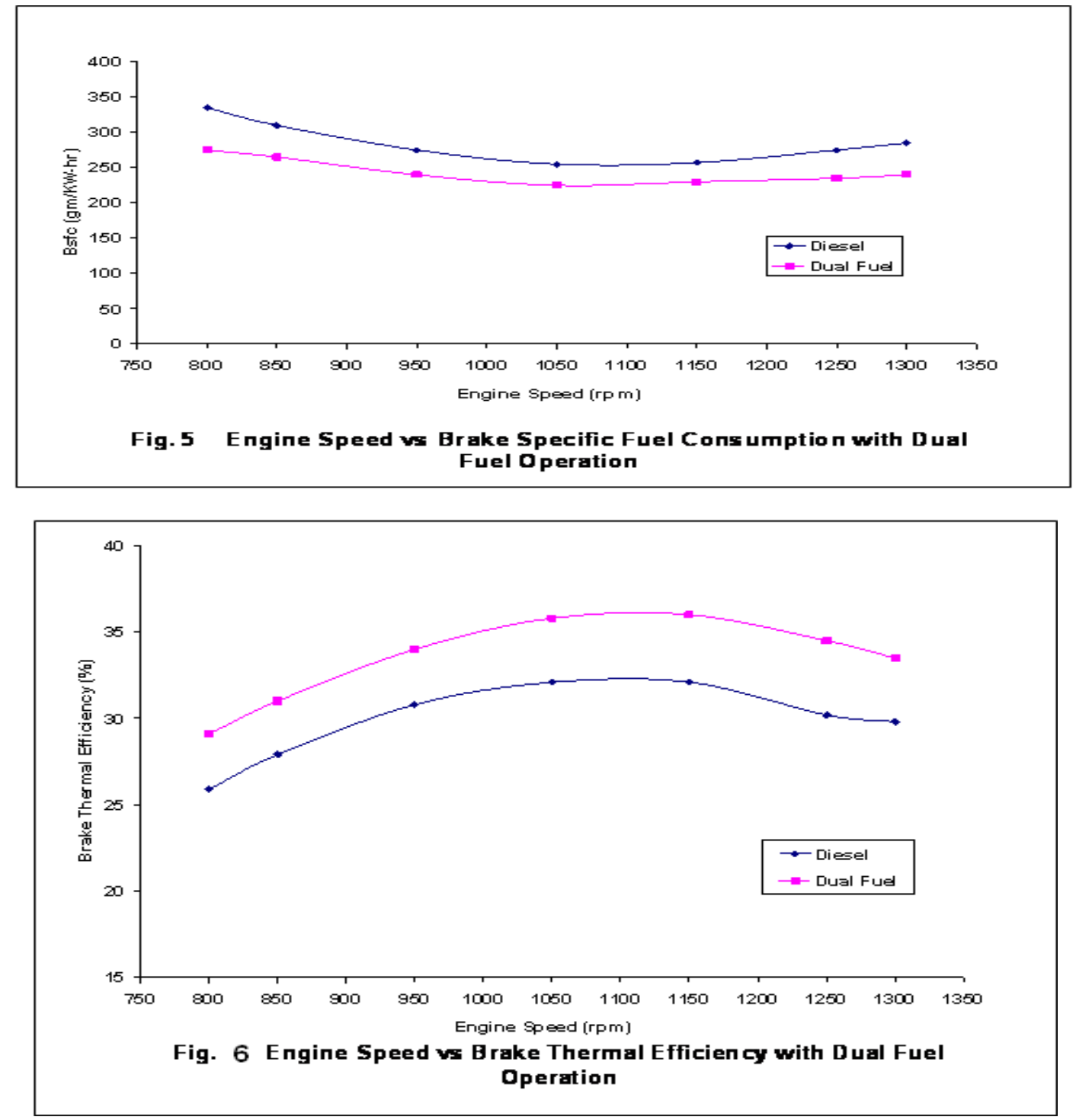

\section{Conclusions}

The experiments are conducted at various speeds ranging from $800 \mathrm{rpm}$ to $1300 \mathrm{rpm}$ for maximum load and the results obtained are drawn below.

- The exhaust gas temperature of diesel fuel is higher than dual-fuel, with an average difference of $20.3^{0} \mathrm{C}$.

- The measured value of the torque for dual-fuel operation is higher than diesel fuel for all engine speeds.

- The engine performance for maximum load there is a considerable improvement in brake power and brake thermal efficiency with a reduction of specific fuel consumption.

\section{References}

[1] Eghbali, B, "Natural gas as a vehicular fuel" SAE 841159, 1984

[2] Freidman, M., Powel et al "Impact of Changes in Transportation and Community Behaviors during the 1996 Summer Olympic Games in Atlanta on Air Quality and Childhood Asthma", Journal of the American Medical Association, vol. 285, February 2001, 897-905.

[3] Kirti Bhandari, Akhil Bansal et al, "Performance and Emissions of Natural Gas Fueled Internal Combustion Engines- A Review”, Journal of Scientific and Industrial Research, Volume 64, May 2005, pp.333-338.

[4] Kaleemuddin Syed, Amba Prasad Rao G., "Development of Dual-Fuel Single Cylinder Natural Gas Engine: An Analysis and Experimental Investigation for Performance and Emission”, American Journal of Applied Sciences 6(5), 2009, pp.929-936

[5] R.G.Papagiannakis, P.N.Kotsiopoulos et al, "Theoretical Study of the Effect of Engine Parameters on Performance and Emissions of a Pilot Ignited Natural Gas Diesel Engine”, Energy, 2009, pp.1-10. 